\title{
Functional Plasticity of Central TRPV1 Receptors in Brainstem Dorsal Vagal Complex Circuits of Streptozotocin-Treated Hyperglycemic Mice
}

\author{
Andrea Zsombok, ${ }^{1,2}$ Muthu D. Bhaskaran, ${ }^{1}$ Hong Gao, ${ }^{2}$ Andrei V. Derbenev, ${ }^{1,2}$ and Bret N. Smith ${ }^{1}$ \\ ${ }^{1}$ Department of Physiology, University of Kentucky College of Medicine, Lexington, Kentucky 40536, and 2Department of Physiology, Tulane University, \\ Health Sciences Center, New Orleans, Louisiana 70112
}

Emerging data indicate that central neurons participate in diabetic processes by modulating autonomic output from neurons in the dorsal motor nucleus of the vagus (DMV). We tested the hypothesis that synaptic modulation by transient receptor potential vanilloid type 1 (TRPV1) receptors is reduced in the DMV in slices from a murine model of type 1 diabetes. The TRPV1 agonist capsaicin robustly enhanced glutamate release onto DMV neurons by acting at preterminal receptors in slices from intact mice, but failed to do so in slices from diabetic mice. TRPV1 receptor protein expression in the vagal complex was unaltered. Brief insulin preapplication restored TRPV1dependent modulation of glutamate release in a PKC- and PI3K-dependent manner. The restorative effect of insulin was prevented by brefeldin A, suggesting that insulin induced TRPV1 receptor trafficking to the terminal membrane. Central vagal circuits critical to the autonomic regulation of metabolism undergo insulin-dependent synaptic plasticity involving TRPV1 receptor modulation in diabetic mice after several days of chronic hyperglycemia.

\section{Introduction}

Type-1 diabetes (T1D) is an autoimmune disease resulting from destruction of insulin-secreting pancreatic islet $\beta$ cells (Tisch and McDevitt, 1996). Diabetes has been handled mainly as a peripheral metabolic disease, but accumulating evidence indicates that the brain plays a critical role in regulating glucose homeostasis via activity of neurons controlling autonomic functions (Oomura, 1980; Undeland et al., 1998; Schwartz and Porte, 2005).

Along with key hypothalamic nuclei, the brainstem dorsal vagal complex (DVC) plays an important role in the autonomic control of feeding, regulation of pancreas and liver metabolism, and other autonomic functions. Neurons in the DVC are able to respond to both hypoglycemia and hyperglycemia (Ferreira et al., 2001; Balfour et al., 2006; Balfour and Trapp, 2007), consistent with their critical role in whole-body energy homeostasis. Acute hyperglycemia or increased glucose concentration in the DVC tends to inhibit vagal output, whereas chronic hyperglycemia causes vagal nerve activity to increase (Laury et al., 1991; Ahrén et al., 1996). Chronically altered vagal function is common in diabetic patients (see Zsombok and Smith, 2009). Hepatic glucose

\footnotetext{
Received April 26, 2011; revised July 15, 2011; accepted Aug. 9, 2011.

Author contributions: A.Z. and B.N.S. designed research; A.Z., M.D.B., H.G., and A.V.D. performed research; A.Z., M.D.B., A.V.D., and B.N.S. analyzed data; A.Z. and B.N.S. wrote the paper.

This work was supported by research grants from NIDDK (R01 DK080901 and DK056132) to B.N.S.; NHLBI (R211HL091293) to A.V.D.; and American Heart Association (GSA 10GRNT4540000) and Tulane Building Interdisciplinary Research Careers in Women's Health (2K12HD043451) to A.Z. We thank Dr. Timothy McClintock for helpful comments on this manuscript.

Correspondence should be addressed to Dr. Bret N. Smith, Department of Physiology, University of Kentucky College of Medicine, MS508 Chandler Medical Center, 800 Rose Street, Lexington, KY 40536. E-mail: bret.smith@uky.edu.

DOI:10.1523/JNEUROSCI.2081-11.2011

Copyright $\odot 2011$ the authors $\quad 0270-6474 / 11 / 3114024-08 \$ 15.00 / 0$
}

production is altered in diabetes, and this substantially involves central autonomic circuits controlling vagal output to the liver (Pocai et al., 2005a,b; Lam et al., 2010). Intact hepatic vagal output is required for a significant portion of the inhibition of gluconeogenesis following central or peripheral administration of insulin, suggesting that increased circulating insulin levels affect neural circuits required to restrain hepatic gluconeogenesis (Pocai et al., 2005b).

The role of transient receptor potential vanilloid type 1 (TRPV1) in diabetes was recently demonstrated (Suri and Szallasi, 2008) and suggests that events controlling T1D development and glucose dysregulation are not only immunological, but also neurological (Tsui et al., 2007). Several reports, mainly associated with diabetic neuropathy, indicate that peripheral TRPV1 receptor activity and protein levels are altered in diabetic models. In primary afferent neurons, TRPV1 expression is upregulated (Rashid et al., 2003), and significant increases in capsaicin sensitivity and proton-activated inward currents were observed in animals with streptozotocin (STZ)-induced diabetes (Hong and Wiley, 2005). In sensory neuron homogenates, total TRPV1 protein was decreased, but increased protein levels were detected on plasma membranes (Hong and Wiley, 2005). Insulin enhanced TRPV1-mediated currents in heterologous expression systems and cultured primary sensory neurons (Van Buren et al., 2005). These observations suggest that deficiencies in insulin signaling and/or enhanced glucose-dependent mechanisms contribute to altered TRPV1 function and complications of diabetes.

Centrally, activity of TRPV1 potently modulates synaptic input to motor neurons of the dorsal motor nucleus of the vagus (DMV), which ultimately regulates visceral function (Derbenev et al., 2006). TRPV1 activity in the DMV alters, for example, 
gastrointestinal function, but central attributes of TRPV1 function associated with diabetes have not been identified. Here, we tested the hypothesis that TRPV1 is functionally downregulated in an insulindependent fashion in putative preganglionic parasympathetic motor neurons of the DMV in a mouse model of T1D, and we determined the cellular mechanism underlying the effect of insulin on TRPV1mediated synaptic modulation in these neurons.

\section{Materials and Methods}

Animals. Male CD-1 mice (5-8 weeks old; Harlan) were used for these experiments. Animals were housed in a vivarium under $12 \mathrm{~h}$ light, $12 \mathrm{~h}$ dark cycle with food and water available ad libitum. The University of Kentucky and Tulane University Animal Care and Use Committees approved all animal procedures.

Streptozotocin injection. Mice were fasted overnight $(6-10 \mathrm{~h})$ and then injected intraperitoneally with STZ (200 mg/kg; Alexis Biochemicals) dissolved in $0.1 \mathrm{M}$ citrate buffer, at $\mathrm{pH}$ 4.5. Control animals received citrate buffer injections. Body weight and blood glucose levels (One Touch Ultra) were monitored before injection and then daily afterward. Mice with blood glucose levels $>300 \mathrm{mg} / \mathrm{dl}(16.6 \mathrm{~mm})$ for at least $3 \mathrm{~d}$ were considered to be hyperglycemic and were used for further experiments.

Brainstem slice preparation. Acute brainstem slices containing the DMV were prepared from male control and STZ-treated hyperglycemic CD-1 mice. Animals were deeply anesthetized by halothane inhalation to effect (Sigma) and then decapitated. The brain was removed and immersed in an ice-cold $\left(0-4^{\circ} \mathrm{C}\right)$ artificial CSF (aCSF) bubbled with $95 \%$ $\mathrm{O}_{2}-5 \% \mathrm{CO}_{2}$. The composition of aCSF was (in $\mathrm{mm}$ ): $124 \mathrm{NaCl}, 3 \mathrm{KCl}, 26$ $\mathrm{NaHCO}_{3}, 1.4 \mathrm{NaH}_{2} \mathrm{PO}_{4}, 11$ glucose, $1.3 \mathrm{CaCl}_{2}$, and $1.3 \mathrm{MgCl}_{2}, \mathrm{pH} 7.3-$ 7.4. Transverse brainstem slices (i.e., coronal plane; $300 \mu \mathrm{m}$ ) containing the DMV were cut with a vibratome. The slices were transferred to a holding chamber, which contained oxygenated aCSF at $34-36^{\circ} \mathrm{C}$ for $1 \mathrm{~h}$ before being transferred to a recording chamber mounted on the fixed stage of an upright microscope (Olympus BX51WI; or Nikon FN1).

Whole-cell patch-clamp recordings. Whole-cell patch-clamp recordings were performed at $34-36^{\circ} \mathrm{C}$ under visual control on an upright, fixed stage microscope equipped with infrared illumination and differential interference contrast optics (IR-DIC). For whole-cell patch-clamp recordings, electrodes $(2-5 \mathrm{M} \Omega$ ) were filled with a solution containing the following (in mM): $130 \mathrm{Cs}^{+}$-gluconate, $1 \mathrm{NaCl}, 5$ EGTA, 10 HEPES, 1 $\mathrm{MgCl}_{2}, 1 \mathrm{CaCl}_{2}, 3 \mathrm{CsOH}, 2-3 \mathrm{Mg}-\mathrm{ATP}, \mathrm{pH}$ 7.3-7.4, adjusted with $5 \mathrm{M}$ $\mathrm{CsOH}$. EPSCs were examined at a holding potential of -60 or $-70 \mathrm{mV}$. Electrophysiological signals were recorded using an Axoclamp 700B amplifier (Molecular Devices), low-pass filtered at $2 \mathrm{kHz}$, and stored to a computer using a Digidata 1440A digitizer and pClamp 10 software (Molecular Devices). Synaptic currents were analyzed offline using pClamp 10 and MiniAnalysis 6.0.3. (Synaptosoft).

Drug application. All recordings were performed with tetrodotoxin (TTX; $1 \mu \mathrm{M}$ ) in the aCSF solution to block action potentials and monitor mEPSCs. The TRPV1 receptor agonist capsaicin ( $1 \mu \mathrm{M}$; Tocris Bioscience), the TRPV1 antagonist capsazepine (CPZ, $10 \mu \mathrm{M})$ or the TRPV1 antagonist $5^{\prime}$-iodoresiniferatoxin ( $5^{\prime}$-iRFT, $1 \mu \mathrm{M}$; Tocris Bioscience), the TRPV4 agonist $4 \alpha$-phorbol 12,13-didecanoate (4- $\alpha$-PDD, $1 \mu \mathrm{M}$; Alexis Biochemicals), and the Golgi disrupting agent brefeldin A ( $5 \mu \mathrm{M}$, Sigma) were dissolved in ethanol and diluted in aCSF (final concentration of ethanol $<0.01 \%$ by volume). A PKC activator, phorbol 12 -myristate 13-acetate (PMA, 1-3 $\mu \mathrm{M}$, Tocris Bioscience); a PKC inhibitor, GF 109203X (BIM, $500 \mathrm{~nm}$ or $2 \mu \mathrm{M}$; Tocris Bioscience); and a PI3K inhibitor, wortmannin ( $3 \mu \mathrm{M}$; Sigma), were dissolved in DMSO and diluted in aCSF (final DMSO concentration $<0.01 \%$ ). Insulin $(1 \mu \mathrm{M}$, Novolin R, Novo Nordisk) was diluted in aCSF.

Statistical analysis. The effect of agonists and antagonists on mEPSC frequency and amplitude were analyzed within individual cells using the Kolmogorov-Smirnov test by comparing 2 min epochs before and after drug application (>200 events each condition). The effects of agonists and antagonists across the neuron groups were analyzed using a paired two-tailed Student's $t$ test, and effects between different groups were analyzed using one-way ANOVA. Number of replicates (i.e., $n$ ) is neurons recorded, with numbers of mice also indicated for each experiment; probability values over the $95 \%$ confidence level $(p<0.05)$ were considered significant; averages obtained across neurons are expressed as the mean \pm SEM.

Western blot detection and quantification. Transverse (i.e., coronal) sections of the brainstem $(400 \mu \mathrm{M})$ were made from control and STZtreated hyperglycemic mice using a vibratome, and the caudal DVC was microdissected to include the DMV and nucleus tractus solitarius. The samples were homogenized at $4^{\circ} \mathrm{C}$ in lysis buffer $(0.5 \mathrm{M}$ HEPES, $3 \mathrm{M} \mathrm{NaCl}$, $1 \mathrm{M} \mathrm{MgCl} 2,0.5$ м EDTA, 0.1 м DTT, $10 \%$ SDS, $10 \%$ deoxycholate, and $0.3 \%$ Triton $\mathrm{X}-100)$ and centrifuged at $13,000 \mathrm{rpm}$ at $4^{\circ} \mathrm{C}$ for $10 \mathrm{~min}$. The supernatant was collected, leaving the pellet behind. Proteins were quantified using Bradford protein assay. Each lane was loaded with $15 \mu \mathrm{g}$ of protein in $7.5 \%$ Tris $\cdot \mathrm{HCl}$ polyacrylamide gels and electrophoresed at 110 $\mathrm{V}$ for 60-90 min. Proteins were then transferred at $200 \mathrm{~mA}$ for $1 \mathrm{~h}$ to polyvinylidene difluoride membranes for Western blot analysis. Membranes were rinsed in PBS and blocked in 1:1 Odyssey blocking buffer/ PBS (Odyssey, Li-COR Biosciences) for $1 \mathrm{~h}$ at room temperature. Membranes were then either incubated $1 \mathrm{~h}$ at room temperature or overnight at $4^{\circ} \mathrm{C}$, with an anti-rat VR1 N terminus (1:2500) (Neuromics) and an anti-mouse $\alpha$-actin (1:1000) primary polyclonal antibodies (Sigma) in 1:1 Odyssey blocking buffer/PBS/0.1\% Tween 20. Following four 5 min washes (PBS $+0.1 \%$ Tween 20 ), membranes were incubated with fluorescence-conjugated goat anti-rabbit IRDye-680 and goat antirabbit IRDye-800 secondary antibodies (IgG; 1:5000 Odyssey) in Odyssey blocking buffer/PBS/0.1\% Tween 20 and $0.01 \%$ SDS for $1 \mathrm{~h}$, followed by four $5 \mathrm{~min}$ washes. After a final $10 \mathrm{~min}$ PBS wash, the membranes were dried and blots were scanned by a densitometer (Odyssey model 9120, Li-COR Biosciences) to quantify band density. Background density was subtracted from the VR1 band density and normalized to $\alpha$-actin, which was used as the loading control. Western blots were analyzed using single-factor ANOVA. Results are reported as the mean \pm SEM; significance was set at $p<0.05$ for all statistical measures.

\section{Results}

TRPV1 activity is altered in STZ-treated hyperglycemic mice Injection of STZ $(200 \mathrm{mg} / \mathrm{kg}$; i.p.) resulted in hyperglycemia within $3 \mathrm{~d}(>300 \mathrm{mg} / \mathrm{dl} ; 16.6 \mathrm{~mm})$, which was maintained for up to 1 week. The mean blood glucose level in STZ-treated mice measured $4 \mathrm{~d}$ after the injection $(528.1 \pm 13.4 \mathrm{mg} / \mathrm{dl}, n=53)$ was significantly higher than in control mice $(178.7 \pm 3.4 \mathrm{mg} / \mathrm{dl}, n=$ $40 ; p<0.05)$. Animals were used for experiments $3-7 \mathrm{~d}$ after STZ treatment.

Synaptic input to motor neurons of the DMV potently regulates autonomic output to the viscera. The frequency and amplitude of action potential-independent miniature EPSCs (mEPSCs) in the DMV was examined in the presence of TTX $(1 \mu \mathrm{M})$ in slices from control and STZ-treated hyperglycemic animals, maintained in normal artificial CSF (aCSF). To analyze the effect of 3-7 d of continuous hyperglycemia and insulin deficiency on TRPV1 receptor activity in the DMV, the TRPV1 agonist capsaicin was applied while recording synaptic currents in DMV neurons, voltage clamped at -60 or $-70 \mathrm{mV}$. Similar to effects in rats (Derbenev et al., 2006), bath application of capsaicin $(1 \mu \mathrm{M})$ significantly and consistently increased the frequency of mEPSCs in DMV neurons from control mice (Fig. $1 A$ ), and this occurred regardless of the anatomical position of the neuron within the nucleus. The effect of capsaicin was observed within $2 \mathrm{~min}$ of the drug reaching the slice and was maximal by $5 \mathrm{~min}$. Under control conditions, the average mEPSC frequency was $11.0 \pm 1.9 \mathrm{~Hz}$ (range $3.4-20.6 \mathrm{~Hz} ; n=10$ cells from 5 mice). After application of capsaicin $(1 \mu \mathrm{M})$, the mean frequency of mEPSCs increased to $17.1 \pm 3.8 \mathrm{~Hz}$ (range $8.1-42.9 \mathrm{~Hz}, 69 \pm 16 \%$ increase; $n=10 ; p<0.05$; Fig. $1 A, C, E)$. There was no significant change in mEPSC amplitude after capsaicin application, confirming that the agonist acted at presynaptic glutamatergic terminals to enhance glutamate release (Derbenev et al., 2006). The average amplitude in neurons from control mice was $16.2 \pm 1.8 \mathrm{pA}$ (range 8-27 
$\mathrm{pA}$ ) and $16.9 \pm 2.3 \mathrm{pA}$ (range $8-30 \mathrm{pA} ; p>$ $0.05)$ after application of capsaicin. In DMV cells in slices from control mice, mEPSC frequency, but not amplitude, was significantly enhanced by capsaicin, similar to results in rats (Derbenev et al., 2006).

Unlike responses in slices from intact mice, application of capsaicin did not increase the frequency of mEPSCs in DMV neurons from STZ-treated, hyperglycemic mice (Fig. $1 B, D, E$ ). Under control recording conditions (i.e., normal aCSF with TTX), the mean mEPSC frequency was $14.4 \pm 3.5 \mathrm{~Hz}$ (range $2.0-35.7 \mathrm{~Hz}$; $n=12$ from 6 mice). After application of capsaicin, the average frequency of $\mathrm{mEP}$ SCs was unchanged $(16.2 \pm 4.0 \mathrm{~Hz} ; 15 \pm$ $11 \%$ change; range $2.3-43.8 \mathrm{~Hz} ; p>$ $0.05)$. The amplitude of mEPSCs in neurons from STZ-treated hyperglycemic mice was $15.8 \pm 1.1 \mathrm{pA}$ (range $11-23 \mathrm{pA}$ ) and $17.9 \pm 1.7 \mathrm{pA}$ after application of capsaicin (range 12-33 $\mathrm{pA} ; p>0.05$ ). The selective effect of capsaicin on mEPSC frequency in control mice was significantly greater than in STZ-treated mice $(p<$ 0.05; Fig. 1).

The background mEPSC frequency was significantly higher in slices from STZ-treated, hyperglycemic mice than in controls $(p<0.01$; Fig. $2 A-C$ ). The average mEPSC frequency was $8.9 \pm 0.9 \mathrm{~Hz}$ (range $1.4-24.2 \mathrm{~Hz} ; n=35$ from 16 mice) in control animals and $13.7 \pm$ $1.3 \mathrm{~Hz}$ (range $2.7-35.7 \mathrm{~Hz} ; n=44$ from 18 mice) in STZ-treated hyperglycemic animals (Fig. $2 A$ ). To determine whether the increased frequency - and therefore the lack of agonist effect-in STZ-treated mice was due to tonic endogenous TRPV1 activity, the effect on mEPSC frequency of a TRPV1 receptor antagonist, $5^{\prime}$-iRFT, was examined. Application of $5^{\prime}$-iRFT $(1 \mu \mathrm{M})$ did not result in a significant change in the frequency of mEPSCs in STZtreated hyperglycemic or control animals (Fig. 2D). In neurons from STZ-treated, hyperglycemic mice, the average frequency was $14.8 \pm 2.1$ (range 10.3-22.9 Hz) before application of 5-iRFT and $12.4 \pm 4.6 \mathrm{~Hz}$ (range $7.5-26.3 \mathrm{~Hz} ; n=5 ; p>0.05$ ) after antagonist application. Another TRPV1 antagonist, capsazepine, was also without effect in any of three cells. Application of $5^{\prime}$ iRFT $(1 \mu \mathrm{M})$ alone did not alter mEPSC frequency in control mice $(n=5 ; p>0.05$; Fig. $2 D)$, but prevented the increase in mEPSC frequency upon capsaicin application.

\section{TRPV1 receptor protein expression}

\section{was not altered in STZ-treated hyperglycemic mice}

Since the ability of TRPV1 receptor activation to enhance glutamate release in the DMV was diminished in slices from STZtreated hyperglycemic mice, the relationship between altered TRPV1 receptor activity and changes in receptor protein expression in the DVC was investigated. The DVC was microdissected from slices of control and STZ-treated hyperglycemic mice. Western blot analyses were made to compare TRPV1 levels in control and STZ-treated hyperglycemic mice. A discrete band at $95 \mathrm{kDa}$, corresponding to the molecular weight of the TRPV1 receptor, was identified by Western blot, consistent with previous studies using this antibody (Stein et al., 2006; Bhaskaran and Smith, 2010). Western blot analysis identified no significant dif- ference in TRPV1 protein expression between the two groups ( $n=8 ; p>0.05$; Fig. 3 ), suggesting that the altered response to TRPV1 activation was not due to diminished TRPV1 expression in STZ-treated hyperglycemic mice.

\section{Incubation with insulin restores the TRPV1 activity}

Slices from STZ-treated, hyperglycemic mice were preincubated with insulin $(1 \mu \mathrm{M} ; 30 \pm 10 \mathrm{~min})$ to determine the effect of insulin restoration on TRPV1 function (Fig. 4). When comparing cells from insulin-treated slices with cells from control slices, there was a small but nonsignificant effect of insulin alone on mEPSC frequency in slices from STZ-treated hyperglycemic mice $(13.7 \pm 1.3 \mathrm{~Hz} ; n=44$ versus $8.8 \pm 2.1 \mathrm{~Hz} ; n=10$ with insulin; $p>0.05$; unpaired $t$ test). However, preincubation with insulin restored the effect of capsaicin on $\mathrm{mEPSC}$ frequency. The average mEPSC frequency in slices from STZ-treated hyperglycemic mice in the continuous presence of insulin for several minutes was $8.8 \pm 2.1 \mathrm{~Hz}$ (range $0.6-22.2 \mathrm{~Hz} ; n=10$ from 6 mice). In the continued presence of insulin, bath application of capsaicin (1 $\mu \mathrm{M})$ significantly increased mEPSC frequency in each cell tested to $14.6 \pm 3.7 \mathrm{~Hz}$ ( $82 \pm 12 \%$ increase; $n=10$; range $1.1-33.2 \mathrm{~Hz}$; $p<0.05)$. The magnitude of the capsaicin-induced increase was significantly greater than in neurons from STZ-treated hyperglycemic animals without insulin incubation ( $p<0.05$; Fig. $4 B)$, and was similar to the capsaicin-induced increase seen in control mice (i.e., $69 \pm 16 \%$; $p>0.05$ ). These data indicate that acute exposure to insulin can restore TRPV1 receptor functionality in DVC neurons from STZ-treated mice.

\section{Insulin modulates TRPV1 receptor activity in a PI3K/ PKC-dependent manner}

Blocking PKC

TRPV1 receptors are known to be sensitive to PKC modulation (Van Buren et al., 2005). Insulin binds insulin receptors (IRs) in 
A
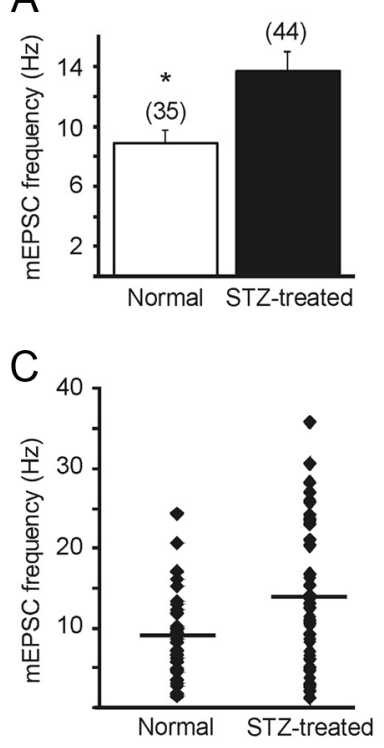

B
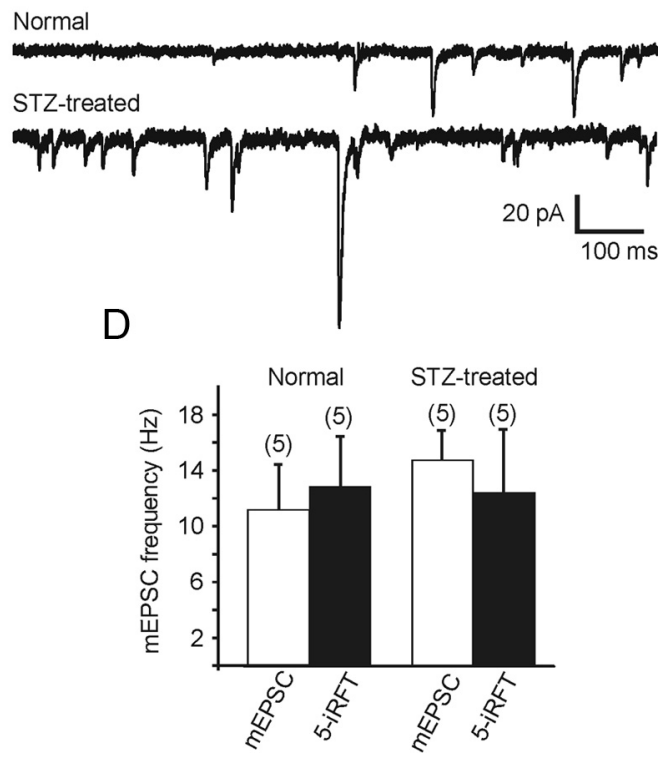

Figure 2. Miniature EPSC frequency was significantly higher in DMV neurons from STZ-treated hyperglycemic mice compared to controls. $A$, Mean group differences in mEPSC frequency in normal and STZ-treated mice. Number of neurons in each group is indicated in parentheses. Asterisk indicates significance between the groups $(p<0.05)$. $\boldsymbol{B}$, Sample recordings of $\mathrm{mEPSC}$ (s observed at holding potential of $-60 \mathrm{mV}$ in neurons from control (upper trace) and STZ-treated hyperglycemic (lower trace) mice. $C$, Combined data showing the distribution of mEPSC frequencies for cells from control and STZ-treated hyperglycemic mice. $D$, Application of the TRPV1 antagonist 5' -iRFT did not significantly change mEPSC frequency in neurons from control or STZ-treated animals, indicating that latent TRPV1 activity was not responsible for the increased mEPSC frequency in treated mice. The number of replicates is shown above each bar.

the brain and, via insulin receptor substrate 2 , a functional component of the IR, activates PI3K and elevates the level of PKC in cultured primary sensory neurons (Van Buren et al., 2005). To determine whether insulin acted via a PKC-dependent mechanism to restore the TRPV1 receptor activity in the DMV in hyperglycemic mice, the effect of a selective and potent PKC inhibitor, bisindolylmaleimide I (BIM) on the capsaicin-induced increase in mEPSC frequency was tested in slices from STZ-treated hyperglycemic mice. Slices were preincubated with insulin $(1 \mu \mathrm{M})$ and BIM (500 nM-2 $\mu \mathrm{M})$ for $30 \mathrm{~min}$ and mEPSCs were recorded before and after capsaicin $(1 \mu \mathrm{M})$ application. The average frequency before capsaicin application was $10.0 \pm 2.1 \mathrm{~Hz}$ (range 2.1-25.0 Hz, $n=9$ from 4 mice). Application of capsaicin failed to increase mEPSCs frequency in the presence of insulin plus the PKC inhibitor $(10.8 \pm 2.3 \mathrm{~Hz}$; range $2.3-25.9 ; 8 \pm 4 \%$ change; $p>0.05$ ). Inhibition of $\mathrm{PKC}$ activity with BIM prevented the insulin-induced restoration of the capsaicin effect in slices from STZ-treated animals (Fig. 5).

We also tested the effect of BIM on slices from control animals, and observed that in the presence of $500 \mathrm{~nm} \mathrm{BIM}$, capsaicin failed to cause a significant increase in the MEPSC frequency, suggesting that the effect of capsaicin also required PKC activity under normal conditions. In this set of control mice, the average mEPSC frequency was $11.6 \pm 2.6 \mathrm{~Hz}$ (range $1.9-21.5 \mathrm{~Hz}$ ) and was $12.7 \pm 2.4 \mathrm{~Hz}$ (range $2.3-21.2 \mathrm{~Hz}$ ) after application of capsaicin $(1 \mu \mathrm{M})$ in the presence of BIM $(n=7$ from 3 mice; $p>$ $0.05)$.

\section{$P K C$ activation}

To verify the involvement of PKC in the reinstatement of TRPV1 function by insulin, we preincubated the slices from STZ-treated animals with a PKC activator, phorbol 12-myristate 13-acetate (PMA; $3 \mu \mathrm{M} ; 20 \mathrm{~min}$ ). Similar to the effect of insulin, preincuba- tion of the slices with PMA restored the effect of capsaicin (Fig. 5). In slices from STZ-treated hyperglycemic mice in the presence of PMA, the average MEPSC frequency was $14.3 \pm 4.4 \mathrm{~Hz}$ (range 2.9-48.3 $\mathrm{Hz}$ ) before capsaicin application and was increased to $24.7 \pm 9 \mathrm{~Hz}$ by the addition of the TRPV1 agonist in each cell tested $(84 \pm 17 \%$ increase; range $4.9-57.1 \mathrm{~Hz}$; $n=10$ from 6 mice; $p<0.05$; Fig. 5 ).

\section{The PI3K pathway}

To verify that the restoration of the response to capsaicin observed after incubation with insulin was due to increased PI3K activity, we examined the effect of the PI3K inhibitor wortmannin on neurons from STZ-treated hyperglycemic mice. Preincubation of slices with wortmannin $(3 \mu \mathrm{M})$ plus insulin $(1$ $\mu \mathrm{M})$ diminished the ability of insulin to restore sensitivity to capsaicin $(1 \mu \mathrm{M})$ versus the restored effect in the presence of insulin alone. In the presence of wortmannin plus insulin, the average mEPSC frequency before was $14.5 \pm 3.0 \mathrm{~Hz}$ (range $1.4-34.4 \mathrm{~Hz}$ ) and was $19.1 \pm 3.9 \mathrm{~Hz}$ after addition of capsaicin (range $1.1-40.1 \mathrm{~Hz} ; n=10$ from 4 mice; $p>0.05$; Fig. 5). In slices from control mice, wortmannin incubation before capsaicin application did not influence the effect of capsaicin. Capsaicin increased mEPSC frequency by $81 \pm 30 \%$ in the presence of wortmannin alone in controls, similar to the increase in the absence of wortmannin $(p>0.05)$. TRPV1 receptor-mediated modulation of glutamate release does not require PI3K activity in intact or STZtreated hyperglycemic animals, but PI3K is required for the full insulin-dependent restoration of capsaicin's effect in slices from STZ-treated, hyperglycemic mice.

\section{Insulin-dependent TRPV1 receptor translocation}

Insulin has been shown to induce rapid delivery of functional TRPV1 receptors to the plasma membrane in cultured DRG cells and in heterologous expression systems (Van Buren et al., 2005). Since total TRPV1 protein expression (i.e., assessed by Western analysis) was similar between the two groups, we reasoned that the insulin-dependent reinstatement of TRPV1 receptor function in the DMV involved receptor translocation to synaptic terminal membrane. To test this hypothesis, brefeldin A was preapplied to slices for $10-55 \mathrm{~min}$ to disrupt the Golgi apparatus and interfere with receptor trafficking, followed by the addition of insulin for $30 \mathrm{~min}$. The average mEPSC frequency in the presence of brefeldin $\mathrm{A}(5 \mu \mathrm{M})$ plus insulin $(1 \mu \mathrm{M}$ ) was $15.5 \pm 3.1 \mathrm{~Hz}$ (range $2.2-32.9 \mathrm{~Hz}$ ) and was $18.2 \pm 2.9 \mathrm{~Hz}$ (range 2.2-33.3 Hz) after addition of capsaicin ( $1 \mu \mathrm{M}$; $n=11$ from 5 mice; $p>0.05$ ). Preincubation of the slices from STZ-treated, hyperglycemic animals with brefeldin A prevented the insulin-dependent reinstatement of the TRPV1-mediated enhanced glutamate release (Fig. 5).

\section{TRPV4 sensitivity was not altered after STZ treatment}

To assess the possibility that TRP receptors were nonspecifically altered in slices from STZ-treated mice, the function of a close TRP family member, TRPV4, was assessed. The effect of the selective TRPV4 agonist 4- $\alpha$ PDD was examined in control and 
A
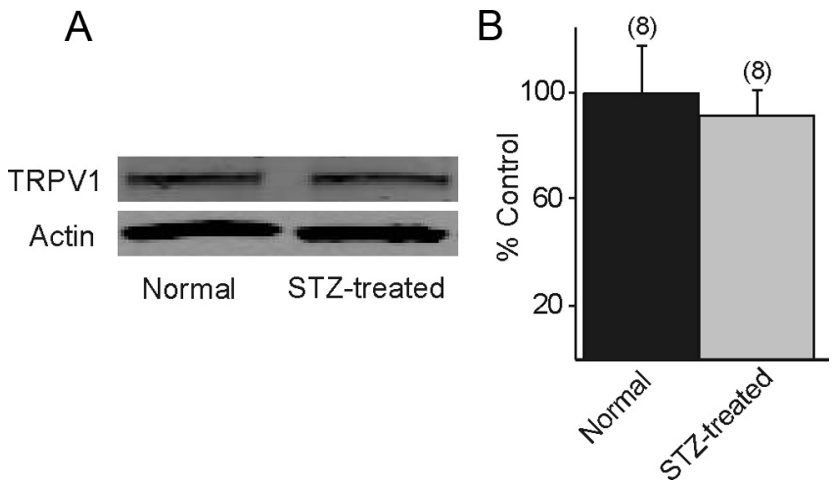

Figure 3. TRPV1 expression levels were not different in STZ-treated hyperglycemic mice. $\boldsymbol{A}$, Western blot showing a band at $95 \mathrm{Kd}$, consistent with TRPV1 expression in the vagal complex from control and STZ-treated hyperglycemic mice. Actin was used as a loading control. B, Western blot densitometry analysis detected no significant difference in TRPV1 protein levels between control and STZ-treated mice. The number of replicates is shown above each bar.

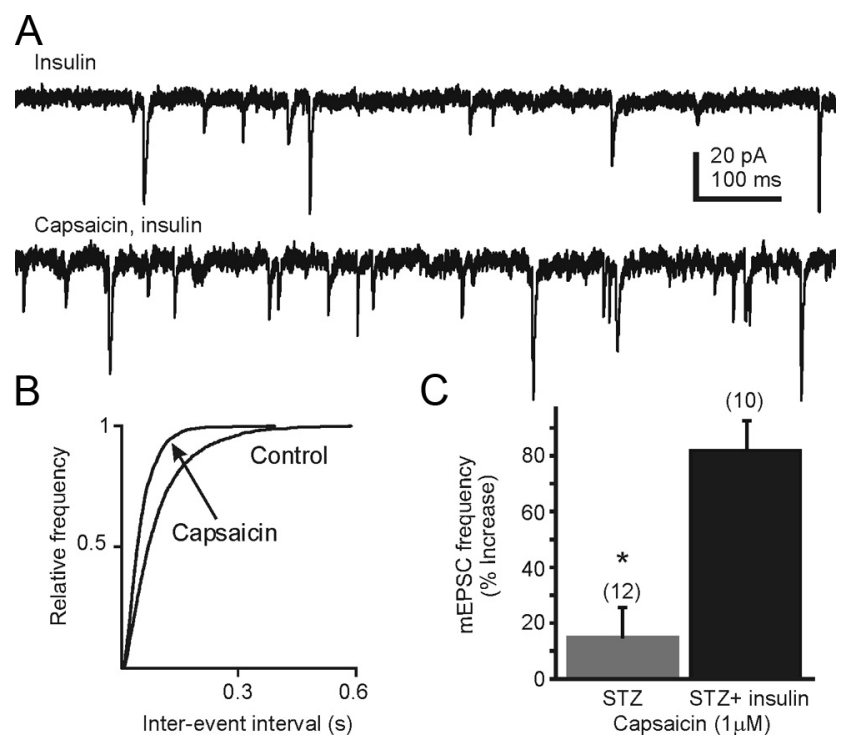

Figure 4. The TRPV1 receptor-mediated increase in glutamate release was reinstated in STZ-treated hyperglycemic mice in the presence of exogenously applied insulin. $\boldsymbol{A}$, Sample recordings of $\mathrm{mEPSC}$ observed at holding potential at $-60 \mathrm{mV}$ in the presence of insulin $(1 \mu \mathrm{m}$; upper trace). Preincubation of the slices with insulin for 20 min restored the capsaicin-induced increase in mEPSC frequency (bottom trace). $\boldsymbol{B}$, Cumulative event probability plots of interevent interval distribution in recordings from STZ-treated mice in the presence of insulin (control) and insulin + capsaicin. C, Mean group changes in mEPSC frequency showing the effect of capsaicin in STZ-treated hyperglycemic mice in the absence and presence of insulin. The number of replicates is shown in parentheses above each bar; the asteriskindicates significant difference in the effect of capsaicin in the presence of insulin $(p<0.05)$.

STZ-treated hyperglycemic animals. Application of 4- $\alpha$ PDD (1 $\mu \mathrm{M}$ ) resulted in a significant increase in mEPSC frequency in slices from both control and STZ-treated hyperglycemic mice $(p<0.05)$. The effect of $4-\alpha \mathrm{PDD}$ was observed within $2 \mathrm{~min}$ of the drug reaching the slice and was maximal by $5 \mathrm{~min}$. The frequency of mEPSCs was increased $50 \pm 12 \%$ by $4-\alpha \mathrm{PDD}$ in DMV neurons from control animals $(10.7 \pm 1.8 \mathrm{~Hz}$; range $1.4-15.2 \mathrm{~Hz}$, control; $16.3 \pm 3 \mathrm{~Hz}$, range $2-24.8 \mathrm{~Hz}, 4-\alpha \mathrm{PDD} ; n=7 ; p<0.05$; Fig. $6 B$ ). Similarly, application of $4-\alpha$ PDD increased mEPSC frequency by $68 \pm 14 \%$ in DMV neurons from STZ-treated hyperglycemic animals (from $12.1 \pm 3.1 \mathrm{~Hz}$; range $1.1-25.6 \mathrm{~Hz}$, control; $19.3 \pm 5.1 \mathrm{~Hz}$; range $2.2-41.9 \mathrm{~Hz}, 4-\alpha \mathrm{PDD} ; n=8 ; p<$ $0.05)$. There was no significant difference in the magnitude of the

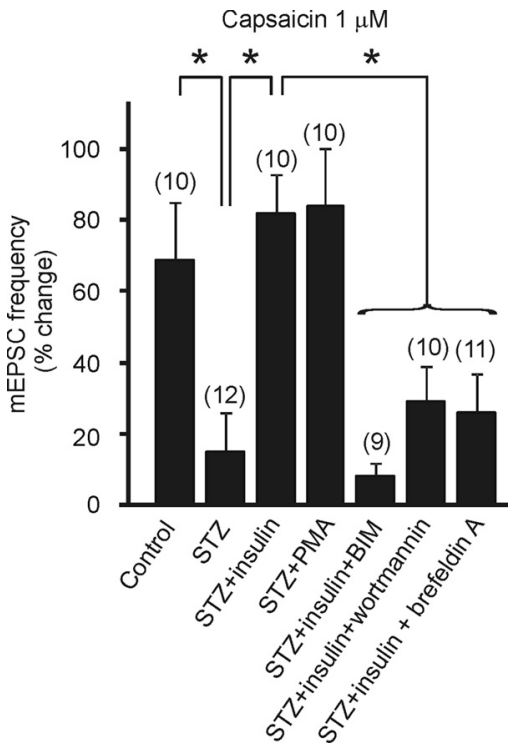

Figure 5. Insulin modulates TRPV1 receptor activity in a PI3 kinase- and PKC-dependent manner. Mean group changes in mEPSC frequency showing the effect of capsaicin under different conditions. Significant differences between effects of capsaicin on mEPSC frequency in DMV neurons from control mice versus those from STZ-treated hyperglycemic mice are illustrated (see Fig. 1). The restorative effect of insulin is also shown (see Fig. 4). Activation of PKC by the addition of PMA restored the effect of capsaicin in slices from STZ-treated hyperglycemic mice. Inhibition of PKC or PI3 kinase activity with BIM or wortmannin, respectively, diminished the ability of insulin to restore the capsaicin-induced mEPSC frequency increase in STZ-treated, hyperglycemic mice. Brefeldin A, which disrupts Golgi function and receptor trafficking, also prevented the restorative effect of insulin on TRPV1-modulated glutamate release. Asterisks indicate significant mEPSC frequency differences between neurons tested in the presence of insulin alone versus in insulin plus kinase or Golgi inhibitors $(p<0.05)$. The number of replicates is shown above each bar.
A

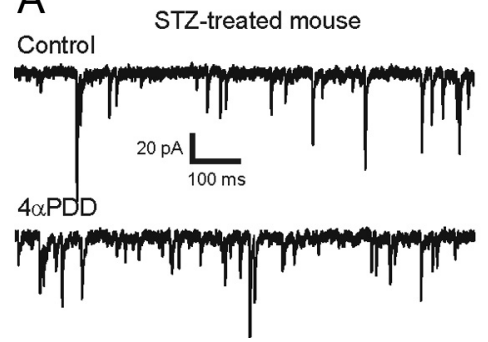

B

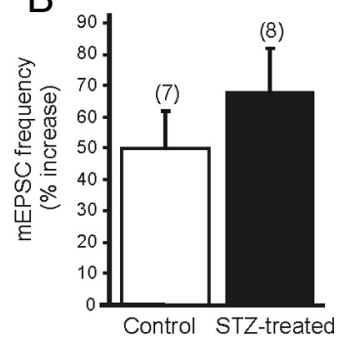

Figure 6. TRPV4 receptor activity was not altered in STZ-treated hyperglycemic mice. $\boldsymbol{A}$, Sample trace showing mEPSCs in DMV neuron from an STZ-treated hyperglycemic mouse in control aCSF (upper trace) and in the presence of $4 \alpha \mathrm{PDD}$ ( $1 \mu \mathrm{m}$; lower trace), a selective TRPV4 receptor agonist. $\boldsymbol{B}$, Mean group changes in $\mathrm{mEPSC}$ frequency showing similar magnitude of $4 \alpha$ PDD-induced increase in control and STZ-treated hyperglycemic mice. Bath application of $4 \alpha \mathrm{PDD}$ significantly increased mEPSC frequency in both control and STZ-treated hyperglycemic mice $(p<0.05)$. The number of replicates is shown above each bar.

effect between the two groups, suggesting that TRPV4 function remained intact in STZ-treated hyperglycemic animals.

\section{Discussion}

Elevated glucose can acutely alter cellular function in the vagal complex (Ferreira et al., 2001; Balfour et al., 2006), and chronically altered excitability in neurons is often associated with compensatory, plastic changes in receptor function. Here, the TRPV1-mediated enhancement of glutamate release in the DMV was suppressed after 3-7 d of frank hyperglycemia due to STZinduced insulin depletion, even when glucose concentration in the slices was normalized and identical between groups of record- 
ings. Prolonged hyperglycemia can induce vagally stimulated insulin release (Laury et al., 1991) and can result in tonically altered vagus nerve activity (Ahrén et al., 1996), independent of insulin availability. Hyperglycemia is associated with increased GABAergic tone in the DVC (Ferreira et al., 2001). Chronic hyperglycemia may alter synaptic balance sufficiently to contribute to the functional receptor changes observed here, including a possibly compensatory increase in glutamatergic contribution. Diminished TRPV1-mediated glutamate release is consistent with reduced synaptic excitation and therefore decreased vagal motor tone, which would be expected to contribute to diabetic gastroparesis accompanying vagal dysregulation (Saltzman and McCallum, 1983). Moreover, since vagal activity tends to inhibit hepatic gluconeogenesis, altered excitability of DMV neurons would be expected to contribute to hepatic glucose dysregulation.

In addition to chronic hyperglycemia, the absence of insulin signaling may also have contributed to an internalization of TRPV1 receptors in synaptic terminals. Consistent with this hypothesis, preapplication of insulin or a PKC activator reinstated the effects of capsaicin. Acute blockade of PKC in slices from normal animals prevented capsaicin's effect, whereas disruption of PKC activity or of receptor trafficking prevented the insulindependent reinstatement of TRPV1 to enhance glutamate release in STZ-treated hyperglycemic animals. Although a number of factors might be responsible for the diminished TRPV1 function, chronically elevated glucose levels and/or diminished insulin levels seem likely to be the most salient features of the effect. Restoring TRPV1 function by insulin or PKC modulation may represent an avenue for restoring DMV neuron activity and normalizing parasympathetic output in diabetic patients.

\section{The role of the CNS in diabetes}

Type- 1 diabetes is generally conceptualized as an autoimmune, metabolic disorder due to $\beta$-cell loss. However, a growing body of evidence suggests that the brain plays an important role in the regulation of energy balance and glucose metabolism (Sandoval et al., 2008; Zsombok and Smith, 2009). It is generally accepted that there is a specific central network receiving afferent information regarding the status of peripheral metabolism via hormonal signaling, which is relevant to energy/glucose balance and regulation (Pocai et al., 2005b; Perez-Tilve et al., 2006; Sandoval et al., 2008). This central network, which includes the DVC, connects the brain with peripheral metabolic processes in the viscera, including hepatic gluconeogenesis, gastrointestinal motility, digestion, and pancreatic exocrine function (Barber and Burks, 1987; Ferreira et al., 2001; Pocai et al., 2005b). These observations support the hypothesis that disruption of the normal physiological balance between sympathetic and parasympathetic output due to dysregulated central synaptic function is a key factor promoting development of the metabolic syndrome.

The autonomic network is centered in hypothalamus and brainstem circuits, which are robustly interconnected. Roles for hypothalamic and brainstem neurons in energy regulation have been demonstrated (Sandoval et al., 2008). Administration of insulin to the paraventricular nucleus (PVN) induced suppression in hepatic gluconeogenesis, which was mediated by the vagus (Pocai et al., 2005b). Specific alteration of glutamate activity in the DVC also affects hepatic glucose production (Lam et al., 2010). The DVC plays a critical role in the autonomic parasympathetic control of energy homeostasis via the vagus nerve, and modulation of neural circuits in this area profoundly alters digestive and metabolic processes.

\section{The TRPV1 receptor in the brain}

The importance of TRPV1 receptor in peripheral sensory systems during diabetes has been established (Razavi et al., 2006; Suri and Szallasi, 2008), but the role of central TRPV1 receptors is not yet as clear. The existence of TRPV1, a nonselective cation channel, has been demonstrated in the brain (Mezey et al., 2000; Cristino et al., 2006), including in DVC where it can be activated by capsaicin or anandamide (Derbenev et al., 2006), resulting in enhanced glutamate release. Notably, anandamide also binds cannabinoid receptors in the DVC (Derbenev et al., 2004), activation of which, if unopposed by TRPV1 binding, would tend to inhibit glutamate release. The expression of TRPV1 is altered peripherally in several diseases affecting metabolism, including diabetes. Activation of PKC induces TRPV1 activity in the absence of another agonist and potentiates the response of TRPV1 to capsaicin (Premkumar and Ahern, 2000). Stimulating PKC with PMA reinstated the TRPV1-mediated enhancement of mEPSC frequency in STZ-treated hyperglycemic mice. This is consistent with the observation that application of BIM, a PKC inhibitor, prevented the capsaicin-induced enhancement of mEPSC frequency in control slices, which further supports the involvement of PKC in TRPV1 activation and enhancement of glutamate release centrally.

The present results in central motor circuits demonstrate that TRPV1 receptor activity is diminished in the brainstem of STZtreated, hyperglycemic mice in an insulin-dependent fashion. However, a reduction in total TRPV1 protein expression levels was not detected in the DVC of T1D mice and the TRPV1mediated response was reinstated by PKC upregulation, suggesting that the receptors were present but functionally unavailable. In the periphery, insulin traffics glucose transporters to the membrane to allow cellular glucose utilization (Kahn and Cushman, 1985). In addition to sensitizing TRPV1 receptors, PKC can also traffic the receptor to the plasma membrane in cultured cells (Van Buren et al., 2005). Application of brefeldin A disrupts receptor trafficking in the vagal complex (Browning et al., 2004) and disrupting receptor trafficking with brefeldin A prevented the insulin-induced reinstatement of the capsaicin effect. Similarly, insulin potentiates TRPV1 function in Xenopus oocytes and neuroblastoma cells (Lilja et al., 2007) in a PI3K- and PKCdependent manner, effects that were due to increased protein expression, increased receptor sensitivity, and membrane translocation (Morenilla-Palao et al., 2004). Our findings are consistent with the hypothesis that insulin potentiates TRPV1 receptor function on glutamatergic synaptic terminals in the DMV by translocating them to the synaptic terminal membrane in a PI3Kand PKC-dependent manner. Unlike TRPV1, the functional expression of TRPV4, which has also been demonstrated to be located centrally (Liedtke et al., 2000; Güler et al., 2002), was not altered, indicating that a nonspecific alteration in TRP family expression or function did not occur.

\section{Insulin in the brain}

Insulin crosses the blood-brain barrier via a saturable transport mechanism (Margolis and Altszuler, 1967; Banks, 2004) and is transported into the brainstem and hypothalamus over twice as rapidly as into whole brain (Banks, 2004), which highlights the importance of these brain areas in glucose metabolism. The brain is insulin independent with respect to glucose utilization, but neuronal insulin receptors are expressed in the DVC (Pardini et al., 2006), and centrally acting insulin regulates peripheral energy homeostasis and glucose metabolism (Obici et al., 2002; Schwartz and Porte, 2005). Here, we show that application of insulin onto 
slices from STZ-treated hyperglycemic animals rapidly restores the capsaicin-induced increase in mEPSC frequency, suggesting a partial reconstitution by insulin of normal synaptic control of vagal output in these animals. The effect of insulin on reinstatement of TRPV1-dependent effects in preganglionic vagal neurons that regulate visceral function represents a potentially novel, insulin-dependent means of regulating metabolism centrally.

\section{The connection between TRPV1 and insulin}

The mEPSC frequency was significantly higher in the brainstem of STZ-treated hyperglycemic mice than in controls, suggesting tonically increased glutamate release in these animals. We tested the hypothesis that the increased mEPSC frequency was due to tonic TRPV1 activation, which could obscure the effects of TRPV1 agonists. However, significant TRPV1 antagonistinduced changes in mEPSC frequency were not detected, indicating that the enhanced mEPSC frequency was unlikely to be due to increased tonic TRPV1 activity. In the hippocampus, insulin enhances NMDA receptor function, increasing channel opening probability by enhancing the number of NMDA receptors in the cell membrane and NR1 subunit surface expression (Skeberdis et al., 2001), but insulin-induced alteration of glutamate receptor function was not overt in the DMV. The basis for the tonically elevated glutamate release in the DMV of STZ-treated hyperglycemic mice remains a subject for future investigation.

Modulation of central TRPV1 function suggests altered DMV output in STZ-treated, hyperglycemic mice, which may contribute to altered glucose metabolism by decreasing the ability of TRPV1 binding to alter excitability of DMV neurons that regulate liver, pancreas, or gastrointestinal viscera. This would be consistent with a dysregulation of hepatic gluconeogenesis, and gastrointestinal responses might include diminished digestive reflexes, depending on the type of postganglionic circuit targeted by the DMV neuron. Whether insulin sensitivity of this circuit is altered in type 2 diabetes is not known, but development of insulin resistance in the DVC could similarly contribute to the development of diabetic symptoms. The observations here support an emerging and significant role of central TRPV1 in regulating and responding to glucose and insulin levels in patients with diabetes, as well as indicating a novel cellular mechanism of insulindependent regulation of synaptic modulation in neurons.

\section{References}

Ahrén B, Sundkvist G, Mulder H, Sundler F (1996) Blockade of muscarinic transmission increases the frequency of diabetes after low-dose alloxan challenge in the mouse. Diabetologia 39:383-390.

Balfour RH, Trapp S (2007) Ionic currents underlying the response of rat dorsal vagal neurones to hypoglycaemia and chemical anoxia. J Physiol 579:691-702.

Balfour RH, Hansen AM, Trapp S (2006) Neuronal responses to transient hypoglycaemia in the dorsal vagal complex of the rat brainstem. J Physiol 570:469-484.

Banks WA (2004) The source of cerebral insulin. Eur J Pharmacol 490:5-12.

Barber WD, Burks TF (1987) Brain-gut interactions: brain stem neuronal response to local gastric effects of substance P. Am J Physiol 253:G369-377.

Bhaskaran MD, Smith BN (2010) Effects of TRPV1 activation in the dentate gyrus of a mouse model of TLE. Exp Neurol 223:529-536.

Browning KN, Kalyuzhny AE, Travagli RA (2004) Mu-opioid receptor trafficking on inhibitory synapses in the rat brainstem. J Neurosci 24:7344-7352.

Cristino L, de Petrocellis L, Pryce G, Baker D, Guglielmotti V, Di Marzo V (2006) Immunohistochemical localization of cannabinoid type 1 and vanilloid transient receptor potential vanilloid type 1 receptors in the mouse brain. Neuroscience 139:1405-1415.

Derbenev AV, Stuart TC, Smith BN (2004) Cannabinoids suppress synaptic input to neurones of the rat dorsal motor nucleus of the vagus nerve. J Physiol 559:923-938.

Derbenev AV, Monroe MJ, Glatzer NR, Smith BN (2006) Vanilloid-mediated heterosynaptic facilitation of inhibitory synaptic input to neurons of the rat dorsal motor nucleus of the vagus. J Neurosci 26:9666-9672.

Ferreira M Jr, Browning KN, Sahibzada N, Verbalis JG, Gillis RA, Travagli RA (2001) Glucose effects on gastric motility and tone evoked from the rat dorsal vagal complex. J Physiol 536:141-152.

Güler AD, Lee H, Iida T, Shimizu I, Tominaga M, Caterina M (2002) Heatevoked activation of the ion channel, TRPV4. J Neurosci 22:6408-6414.

Hong S, Wiley JW (2005) Early painful diabetic neuropathy is associated with differential changes in the expression and function of vanilloid receptor 1. J Biol Chem 280:618-627.

Kahn BB, Cushman SW (1985) Subcellular translocation of glucose transporters: role in insulin action and its perturbation in altered metabolic states. Diabetes Metab Rev 1:203-227.

Lam CK, Chari M, Su BB, Cheung GW, Kokorovic A, Yang CS, Wang PY, Lai TY, Lam TK (2010) Activation of N-methyl-D-aspartate (NMDA) receptors in the dorsal vagal complex lowers glucose production. J Biol Chem 285:21913-21921.

Laury MC, Takao F, Bailbe D, Penicaud L, Portha B, Picon L, Ktorza A (1991) Differential effects of prolonged hyperglycemia on in vivo and in vitro insulin secretion in rats. Endocrinology 128:2526-2533.

Liedtke W, Choe Y, Martí-Renom MA, Bell AM, Denis CS, Sali A, Hudspeth AJ, Friedman JM, Heller S (2000) Vanilloid receptor-related osmotically activated channel (VR-OAC), a candidate vertebrate osmoreceptor. Cell 103:525-535.

Lilja J, Laulund F, Forsby A (2007) Insulin and insulin-like growth factor type-I up-regulate the vanilloid receptor-1 (TRPV1) in stably TRPV1expressing SH-SY5Y neuroblastoma cells. J Neurosci Res 85:1413-1419.

Margolis RU, Altszuler N (1967) Insulin in the cerebrospinal fluid. Nature 215:1375-1376.

Mezey E, Tóth ZE, Cortright DN, Arzubi MK, Krause JE, Elde R, Guo A, Blumberg PM, Szallasi A (2000) Distribution of mRNA for vanilloid receptor subtype 1 (VR1), and VR1-like immunoreactivity, in the central nervous system of the rat and human. Proc Natl Acad Sci U S A 97:3655-3660.

Morenilla-Palao C, Planells-Cases R, García-Sanz N, Ferrer-Montiel A (2004) Regulated exocytosis contributes to protein kinase C potentiation of vanilloid receptor activity. J Biol Chem 279:25665-25672.

Obici S, Zhang BB, Karkanias G, Rossetti L (2002) Hypothalamic insulin signaling is required for inhibition of glucose production. Nat Med $8: 1376-1382$.

Oomura Y (1980) Input-output organization of the hypothalamus relating to food intake behavior. In: Handbook of the hypothalamus, Vol 2, Physiology of the hypothalamus (Morgane PJ, Panskepp J, eds), pp 557-620. New York: Marcel Dekker.

Pardini AW, Nguyen HT, Figlewicz DP, Baskin DG, Williams DL, Kim F, Schwartz MW (2006) Distribution of insulin receptor substrate-2 in brain areas involved in energy homeostasis. Brain Res 1112:169-178.

Perez-Tilve D, Stern JE, Tschöp M (2006) The brain and the metabolic syndrome: not a wireless connection. Endocrinology 147:1136-1139.

Pocai A, Lam TK, Gutierrez-Juarez R, Obici S, Schwartz GJ, Bryan J, AguilarBryan L, Rossetti L (2005a) Hypothalamic K(ATP) channels control hepatic glucose production. Nature 434:1026-1031.

Pocai A, Obici S, Schwartz GJ, Rossetti L (2005b) A brain-liver circuit regulates glucose homeostasis. Cell Metab 1:53-61.

Premkumar LS, Ahern GP (2000) Induction of vanilloid receptor channel activity by protein kinase C. Nature 408:985-990.

Rashid MH, Inoue M, Bakoshi S, Ueda H (2003) Increased expression of vanilloid receptor 1 on myelinated primary afferent neurons contributes to the antihyperalgesic effect of capsaicin cream in diabetic neuropathic pain in mice. J Pharmacol Exp Ther 306:709-717.

Razavi R, Chan Y, Afifiyan FN, Liu XJ, Wan X, Yantha J, Tsui H, Tang L, Tsai S, Santamaria P, Driver JP, Serreze D, Salter MW, Dosch HM (2006) TRPV1 + sensory neurons control beta cell stress and islet inflammation in autoimmune diabetes. Cell 127:1123-1135.

Saltzman MB, McCallum RW (1983) Diabetes and the stomach. Yale J Biol Med 56:179-187.

Sandoval D, Cota D, Seeley RJ (2008) The integrative role of CNS fuel- 
sensing mechanisms in energy balance and glucose regulation. Annu Rev Physiol 70:513-535.

Schwartz MW, Porte D Jr (2005) Diabetes, obesity, and the brain. Science 307:375-379.

Skeberdis VA, Lan J, Zheng X, Zukin RS, Bennett MV (2001) Insulin promotes rapid delivery of N-methyl-D- aspartate receptors to the cell surface by exocytosis. Proc Natl Acad Sci U S A 98:3561-3566.

Stein AT, Ufret-Vincenty CA, Hua L, Santana LF, Gordon SE (2006) Phosphoinositide 3-kinase binds to TRPV1 and mediates NGF-stimulated TRPV1 trafficking to the plasma membrane. J Gen Physiol 128:509-522.

Suri A, Szallasi A (2008) The emerging role of TRPV1 in diabetes and obesity. Trends Pharmacol Sci 29:29-36.
Tisch R, McDevitt H (1996) Insulin-dependent diabetes mellitus. Cell 85:291-297.

Tsui H, Razavi R, Chan Y, Yantha J, Dosch HM (2007) 'Sensing' autoimmunity in type 1 diabetes. Trends Mol Med 13:405-413.

Undeland KA, Hausken T, Gilja OH, Aanderud S, Berstad A (1998) Gastric meal accommodation studied by ultrasound in diabetes. Relation to vagal tone. Scand J Gastroenterol 33:236-241.

Van Buren JJ, Bhat S, Rotello R, Pauza ME, Premkumar LS (2005) Sensitization and translocation of TRPV1 by insulin and IGF-I. Mol Pain $1: 17$.

Zsombok A, Smith BN (2009) Plasticity of central autonomic neural circuits in diabetes. Biochim Biophys Acta 1792:423-431. 